\title{
An easy and fast technique for brain perfusion in birds
}

\author{
COSME SALAS, D. I. ONYEKWERE, and J. MARTÍN RAMIREZ \\ University of Seville, Seville, Spain
}

\begin{abstract}
An easy technique for perfusion of the brain in birds is described. This procedure involves perfusion through the carotid artery instead of the traditional transcardian method. The advantages of using this technique for psychobiological studies are stressed.
\end{abstract}

The behavior of birds, especially that of the genera Columba and Gallus, is frequently studied within a neural context. For example, investigators often wish to study the way neuroanatomical and neurophysiological manipulations affect these birds' behavior. For these studies, a correct perfusion of the birds' nervous tissue is usually needed.

The usual method for perfusion in mammals, through the heart (via the brachiocephalic artery), is complicated and difficult in birds because of the enormous size of their pectoral muscles and sternum, which must be damaged in order to get to the heart. For this reason, perfusion in birds has been carried out for many years through the carotid artery (e.g., Arends \& Zeigler, 1986; Ramirez \& Delius, 1979; Ramirez, Salas, \& Portavella, 1988; van Tienhoven \& Juhasz, 1962; Wild, 1987). This is also a faster method than transcardian perfusion because only the head is perfused, and not the entire body, which reduces the volume of the liquid to be passed through the perfusion.

However, when carried out incorrectly, this alternative method may result in unsatisfactory perfusions such as those observed in a few published microphotographs of nervous tissue in which artifacts are shown. In order to avoid these obstacles, we have developed a simple method for brain perfusion through the carotid artery. Our procedure is highly reliable and less time-consuming than the traditional method, according to our neuroanatomical studies.

\section{PROCEDURE}

First, an intravenous injection of an anticoagulant (we use $0.5-1.0 \mathrm{ml}$ sodium heparin) is given through the axillar vein, which is easily located in birds: it is superficial, quite thick, and therefore visible, which makes for easy manipulation. It is best to allow some time after the injection of the anticoagulant in order for it to be sufficiently distributed through the circulatory system of the animal.

This study was supported by the Humboldt Foundation and by Grant 541A.6-60/1988 of the Junta de Andalucía. Correspondence may be addressed to J. Martín Ramirez, Department of Psychobiology, Apartado de Correos 3128, University of Seville, 41080-Seville, Spain.
The next step is the intraperitoneal administration of lethal doses of a barbiturated anesthetic.

The third step is the exposition of the arteria carotis communis (see Figure 1). First, a wide longitudinal cut is made in the lowest part of the neck and in the crop. The esophagus and the trachea are laid aside so that the muscles of the neck are left uncovered. Then the skin is cut to the lower jaw to expose the point where the arteria carotis communis branches out from the arteria carotis interna and the arteria carotis externa. Both of the arteria carotis communis (on each side) are located very deep, close to the medioventral part of the neck bone; they run longitudinally to the neck, parallel and close together, under the muscles.

To reach the carotid arteries, the neck muscles must be torn between two vertebrae with a thin-but not very sharp-forceps. It is important to look for these vessels between the two vertebrae near the point where the neck meets the trunk, since this facilitates an upper insertion of the cannula in case the vessel gets broken during the cannulating process.

The next step is cannulation of one of the two arteries. One carotid artery is held carefully with forceps, and the tip of a cannula is introduced into its lumen. Next, a thread is knotted around the artery, holding it against the cannula to keep the cannula from slipping, as shown in

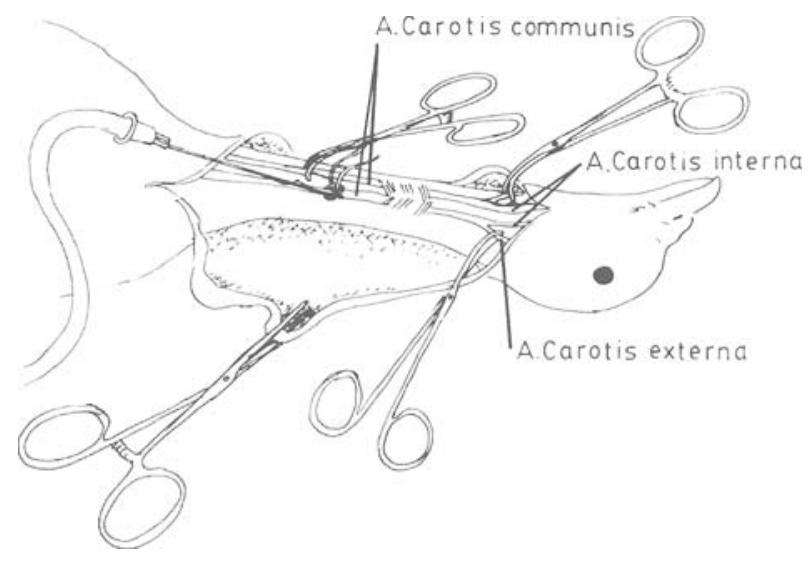

Figure 1. Exposition of the carotid artery. 
Figure 2 . The cannula is then carefully inserted in a flexible rubber tube with a corresponding adapter. The cannula and the rubber tube are fastened to the animal with plaster to avoid their displacement due to eventual movement. Only one carotid artery is cannulated because birds have intercarotid anastomosis (Figure 3) (Baumel, 1962; Baumel \& Gerchman, 1968; Ghetie, Chitescu, Cotofa, \& Hillebrand, 1981), which makes possible the perfusion of both hemispheres of the brain by injection into only one artery.

To prevent the introduced liquid from entering other vessels, thereby decreasing its flow toward the brain, the uncannulated arteria carotis communis as well as the two arteria carotis externa must be pinched with forceps.

Next, the jugular veins, which run superficially through the subcutaneous tissue, are cut to open the circuit for the injected liquid.

Once the above preparation is completed, the animal is ready for perfusion. Saline solution and the fixing liquid are successively pumped into the bird by manual perfusion with a syringe, by gravity, or with a pressurized system. It is advisable to add a vasodilator (e.g., sodium nitrate $1 \%$ or sodium nitroferricyanide $0.5 \%$ ) to the saline. The liquid coming out of the jugular veins serves as a continuous control of the correctness of the perfusion.

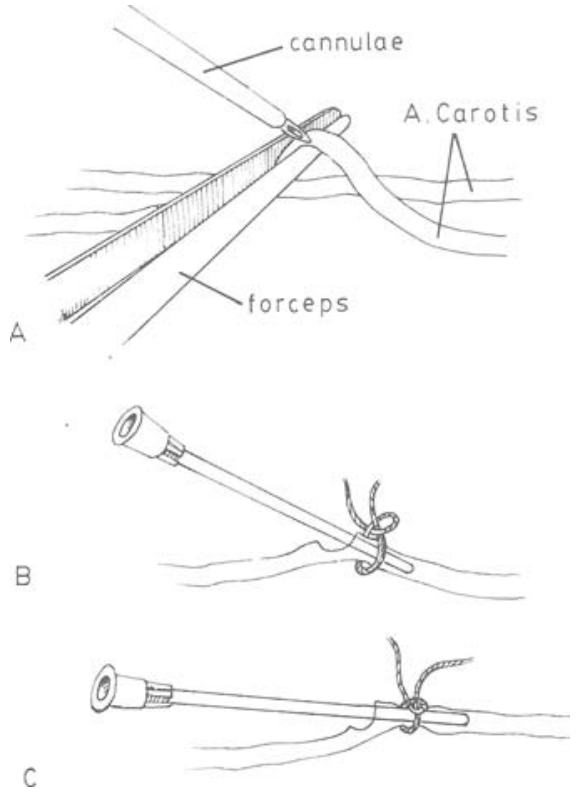

Figure 2. Cannulation of the vessel.

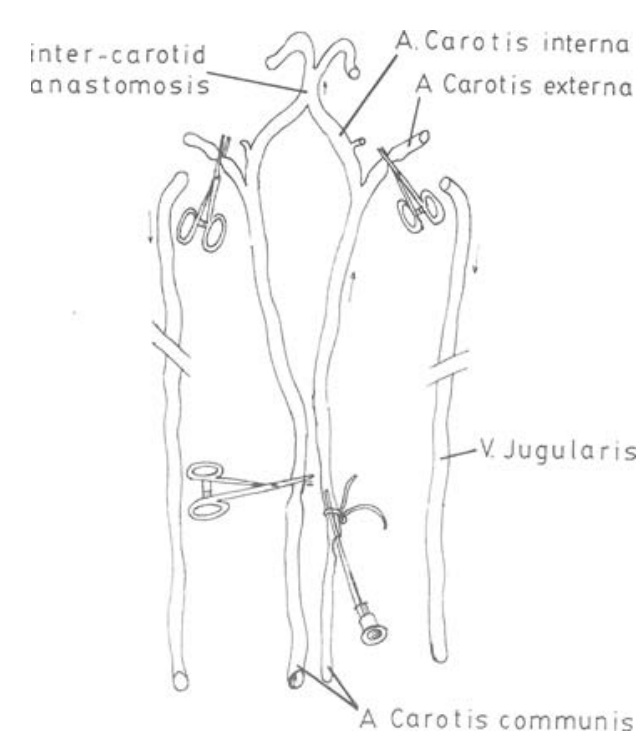

Figure 3. Intercarotid anastomosis and appropriate placement of forceps.

This procedure allows a correct fixation of the nervous tissue and assures a high level of cleanliness of the blood vessels.

\section{REFERENCES}

Arends, J. J. A., \& Zeigler, H. P. (1986). Anatomical identification of an auditory pathway from a nucleus of the lateral lemniscal system of the frontal telencephalon (nucleus basalis) of the pigeon. Brain Research, 398, 375-381.

Baumel, J. J. (1962). Asymmetry of encephalic arteries in the pigeon (Columba livia). Anatomischer Anzeiger, 111, 91-102.

BAUMEL, J. J., \& GerChMAN, L. (1968). The avian inter-carotid anastomosis. American Journal of Anatomy, 122, 1-18.

Ghetie, V., Chitescu, S. T., Cotofa, V., \& Hillebrand, A. (1981). Atlas de anatomía de las aves domésticas. Saragossa, Spain: Editorial Acribia.

Ramirez, J. M., \& Delius, J. D. (1979). Aggressive behavior of pigeons: Suppression by archistriatal lesions. Aggressive Behavior, 5, 3-17.

Ramirez, J. M., Salas, C., \& Portavella, M. (1988). Offense and defense after lateral septal lesions in Columba livia. International Journal of Neuroscience, 41, 241-250.

van TIEnhoven, A., \& JUHASZ, L. P. (1962). The chicken telencephalon, diencephalon and mesencephalon in stereotaxic coordinates. Journal of Comparative Neurology, 118, 185-197.

WILD, J. M. (1987). Thalamic projections to the paleostriatum and neostriatum in the pigeon (Columba livia). Neuroscience, 20, 305-327. 